\title{
The role of celecoxib for colorectal cancer treatment: a systematic review
}

\author{
Xiaohan Zhou", Xiuyun Wang", Yaqin Zhao, Cheng Yi \\ Department of Medical Oncology, West China Hospital, Sichuan University, Chengdu 610041, China \\ Contributions: (I) Conception and design: X Zhou, X Wang, C Yi; (II) Administrative support: C Yi; (III) Provision of study materials or patients: \\ X Zhou, X Wang, C Yi; (IV) Collection and assembly of data: X Zhou, X Wang, Y Zhao; (V) Data analysis and interpretation: All authors; (VI) \\ Manuscript writing: All authors; (VII) Final approval of manuscript: All authors. \\ \#These authors contributed equally to this work. \\ Correspondence to: Cheng Yi. Department of Medical Oncology, West China Hospital, Sichuan University, No. 37 Guoxuexiang, Chengdu 610041, \\ China. Email: yicheng6834@163.com.
}

Background: Some evidence has suggested that the Cox- 2 inhibitor, celecoxib, might improve the survival
outcomes in cancer patients. However, the association between celecoxib use and treatment response
in colorectal cancer (CRC) patients remains controversial. Thus, a summary on current evidence was
performed.
Methods: We conducted an electronic search using (PubMed, Web of Science, Embase, and CNKI) to identify relevant peer-reviewed articles, up to March 2018. Eligible study designs included randomized controlled trials (RCTs) and uncontrolled trials (UCTs) with the single experimental arm. The included trials evaluated the effect of adding celecoxib to conventional treatments for patients with CRC on overall response rate (ORR), disease control rate (DCR), pathological response, survival indices, and toxicities.

Results: The final analysis included 12 trials with a total of 621 patients. In this study, a qualitative summary and meta-analysis was performed due to insufficient RCTs. The addition of celecoxib showed improvement of pathological response but had no effects on ORR ( $R R=1.09 ; 95 \% \mathrm{CI}, 0.62-1.92 ; \mathrm{P}=0.76$ ) and DCR ( $\mathrm{RR}=1.09 ; 95 \% \mathrm{CI}, 0.94-1.27 ; \mathrm{P}=0.25)$. The impact of celecoxib on survival indices remains unclear. Meta-analysis on toxicities suggests that celecoxib is well tolerated with a decreased risk of oral mucositis ( $\mathrm{RR}=0.35$; 95\% CI, 0.18-0.67; $\mathrm{P}=0.002$ ).

Conclusions: Results showed the potential benefits of celecoxib in the treatment of resectable CRC compared with chemotherapy or chemoradiotherapy alone, but there were no effects on ORR/DCR or survival indices. The safety profile was identified in the meta-analysis among CRC patients. The benefit versus harm needs to be carefully considered when celecoxib is recommended in patients with a history of cardiac diseases. In this review, part of the evidence was evaluated from non-RCTs, so further well-designed RCTs in this field are urgently required to confirm our finding.

Keywords: Celecoxib; colorectal cancer (CRC); efficacy; safety

Submitted May 05, 2018. Accepted for publication Nov 08, 2018.

doi: $10.21037 /$ tcr.2018.11.22

View this article at: http://dx.doi.org/10.21037/tcr.2018.11.22

\section{Introduction}

Colorectal cancer (CRC) is one of the most common malignancies worldwide, and its incidence is increasing. It is predicted that by 2030, there will be a substantial increase in the number of newly diagnosed CRC cases worldwide with an $80 \%$ rise in deaths from CRC (1). Currently, the mainstream therapeutic approaches of CRC are based on surgery, chemotherapy and irradiation. In the metastatic setting, regimens such as FOLFOX or FOLFIRI are the mainstay of standard first-line chemotherapy (2). 
Intensified chemotherapeutic regimens in the first-line setting have been shown to prolong progression-free survival and/or overall survival in multiple randomized trials (3-5).

However, two-thirds of patients do not received chemotherapy until progression because of intolerable toxicities, such as vomiting, nausea, diarrhea, myelosuppression, cardiovascular toxicity and mucositis of the oral cavity. CRC survival outcomes are not satisfactory enough; therefore future research into the combination therapy with the novel agents or novel use of existing agents is required. Overall, the improvement of prognosis in CRC patients will mostly depend on the development of effective systemic therapies, which combine conventional treatments with other agents through novel mechanisms.

Currently, many widely used clinical drugs have attracted the attention of researchers in the anti-tumor field because of their versatile properties with a favorable cost performance (6-8).

The cyclooxygenase $(\mathrm{COX})$ is the rate-limited enzyme in the pathway to synthesize prostaglandin. Cyclooxygenase-2 (COX-2) and Cox-1 are both isoforms of COX (9). COX-1 is constitutively expressed in most tissues and participates in the mediation of various physiologic functions. Conversely, COX-2 is undetectable in most normal tissues but can be rapidly induced by oncogenes, growth factors, tumor promoters, and cytokines (10). As far as we are aware, COX-2 and its downstream factors are able to promote tumor growth, chemoresistance, angioneogenesis and to inhibit the cellular apoptosis $(11,12)$.

Thus, Cox-2 is observed to be overexpressed in premalignant and malignant tissues, which implicates that COX-2 may be a favorable target for malignancy treatment (13). Also, increased expression of COX-2 has been found to be associated with poor patient prognosis in multiple malignancies (14-16). Preclinical studies indicated that COX-2 inhibitors improved radiation response and decreased tumor microenvironment density which can increase the delivery of drugs, especially macromolecular drugs (17).

Currently, celecoxib, a highly selective oral COX2 inhibitor, is used for arthritis patients at a dose of 200 $\mathrm{mg}$ bid (bis in die) in clinics. Clinical trials suggested an ameliorated safety profile of celecoxib compared with nonselective COX inhibitors, like aspirin, in gastrointestinal and renal toxicity (18). Furthermore, a double-blind placebo-controlled study demonstrated that a higher dose of $400 \mathrm{mg}$ bid of celecoxib could lead to a significant reduction in the number of colorectal polyps (19). The similar effect of celecoxib was also observed in the Min mouse model of the human CRC-predisposing syndrome, adenomatous polyposis coli (APC) (20). Thus, celecoxib is the only NSAID that has been approved by the FDA for adjuvant treatment of patients with familial adenomatous polyposis (FAP) since December 1999.

We hypothesized that the COX-2 inhibitor, celecoxib, would improve the prognostic outcomes of CRC patients by combining it with current routine chemotherapy, radiotherapy or CRT. Recent studies investigating the antitumor effects of cox-2 inhibitors reported inconsistent conclusions in various tumor types, so it is still difficult to determine the impact of adding celecoxib to routine treatment in CRC. Accordingly, comprehensive reviews are required to evaluate the clinical efficacy and safety of celecoxib combined with conventional therapy in CRC patients.

\section{Methods}

\section{Literature search strategy}

A comprehensive literature search was performed in the PubMed, Web of Science, Embase, and China National Knowledge Infrastructure (CNKI) from the earliest available data to March 2018. We used Medical Subject Heading (MESH) terms and keywords related to "Celecoxib" ("Celebrex", "Cyclooxygenase 2 Inhibitors", "Cyclooxygenase 2 Inhibitor", "COX-2 Inhibitors", "COX-2 Inhibitor"); "colorectal neoplasms" ("colorectal tumor", "colorectal cancer", "colorectal carcinoma"); "colonic neoplasms" ("colon neoplasms", "colonic carcinoma", "colon cancer", "colon tumor"); "rectal neoplasms" ("rectum neoplasms", "rectum cancer", "rectal carcinoma, rectal cancer").

\section{Inclusion and exclusion criteria}

Studies were checked for the following criteria: (I) intervention studies included randomized controlled trials (RCTs) and uncontrolled trials (UCTs) lacking a control group and/or randomization); (II) the studies enrolled patients with histologically diagnosed resectable/ unresectable CRC; (III) the studies had at least one of following outcome measures as their endpoints, including ORR (CR + PR), DCR (CR + PR + SD), pathological response, survival index and toxicity, or providing sufficient data to calculate these values. We included the study 
containing the most abundant information, if more than one paper was based on the same clinical study.

Exclusion criteria were the following: (I) the study was case report, review meta-analysis, cell line study or animal study; (II) the study had no individual data on CSC alone; (III) the study reported duplicated results or unavailable data.

\section{Data extraction/assessment of methodological quality}

Characteristics of each study were extracted by two investigators (X Zhou/Y Zhao) independently after scanning the title, abstract and full text. The collected information included patient characteristics, interventions, and prognostic outcomes. Regarding the treatment-related toxicity, we summarized the grade 1-4 effects of gastrointestinal events (diarrhea, vomiting, and nausea), leukopenia, and oral mucositis.

The quality of the design and report of studies was quantitatively assessed by using the Downs and Black checklist (21) which provides a reliable quality index for both RCTs and non-randomized studies. This checklist consists of 27 items which are distributed over five subscales: reporting [1-10], external validity [11-13], bias [14-20], confounding [21-26] and power [27]. All items can be answered by 'Yes' (1 point), 'No' (0 points) or 'Unknown' (0 points). Downs and Black checklist used in our studies is shown in the Table S1. Any disagreements were resolved by consensus between two reviewers. When necessary, disputes were resolved by consultation with a third reviewer (C Yi).

\section{Statistical analysis}

Dichotomous data, including ORR, DCR, and toxicities, were compared with a pooled risk ratio (RR) with a $95 \%$ confidence interval (CI) and the results were presented graphically in the form of a forest plot (22). Heterogeneity between clinical trials was assessed by using $\chi^{2}$ test, with the significance level set to $\mathrm{P}<0.1$ (23) and was expressed by using the $\mathrm{I}^{2}$ index, which describes the proportion of total variation among the studies because of heterogeneity rather than chance. If statistical heterogeneity was observed $\left(\mathrm{I}^{2}>50 \%\right)$, a meta-analysis was performed using a randomeffect (DerSimonian and Laird method). Otherwise, the fixed-effect model (Mantel-Haenszel method) was performed $(24,25)$.

The meta-analyses in our review were performed by RevMan 5.3 software (RevMan software, version 5.3, Cochrane Collaboration, Oxford, UK).

\section{Results}

\section{Eligible studies and quality assessment}

The electronic database search identified a total of 1,649 articles. After screening of titles and abstracts, we excluded 528 articles that did not meet our inclusion criteria. After carefully examining the full text, we excluded 38 studies for the following reasons: discrepancy of the target population $(n=12)$, discrepancy of intervention $(n=17)$, lack of sufficient data $(n=3)$, conference abstract $(n=6)$. Three additional articles were added by checking the reference list of the included articles.

As a result, 12 studies, comprising a total of 621 CRC patients, were included in our systematic review. The participant flow diagram for the study inclusion in this review is shown in Figure 1.

\section{Characteristics of the eligible studies}

The baseline characteristics and the quality index of included studies are summarized in Tables 1,2.

Among the 12 included studies, 5 studies were RCTs (26-30), whereas the other 7 UCTs were conducted using single-arm design (31-37). Every participant was diagnosed with advanced unresectable or resectable CSC tumors. The basic chemotherapy regimens for CRC were varied. Among trials, chemotherapies included standard regimen, like FOLFIRI, mFOLFOX6, etc. Only Chan et al. (35) applied a combination of celecoxib and cetuximab. Cetuximab is an antibody against the ligand-binding domain of the epithelial growth factor receptor (EGFR). More details on regimens are summarized in Tables 1,2, and heterogeneity in the dose of celecoxib has to be considered among the included studies.

\section{Pathologic response}

Pathologic response is a way to measure response to neoadjuvant therapy. It is evaluated by pathological examination of T-downstaging, $\mathrm{N}$-downstaging and Dworak regression grading of the surgical resection specimens following the completion of neoadjuvant therapy. $\mathrm{T}$ - and $\mathrm{N}$-downstaging are defined as the absence of residual invasive cancer on $\mathrm{H} \& \mathrm{E}$ stains of the complete resected tumor specimen and those of the sampled regional lymph nodes. Dworak regression is also scored on $\mathrm{H} \& \mathrm{E}$ stains of the resection specimen as described above (38): grade 0 , no regression; grade 1 , minimal regression; grade 


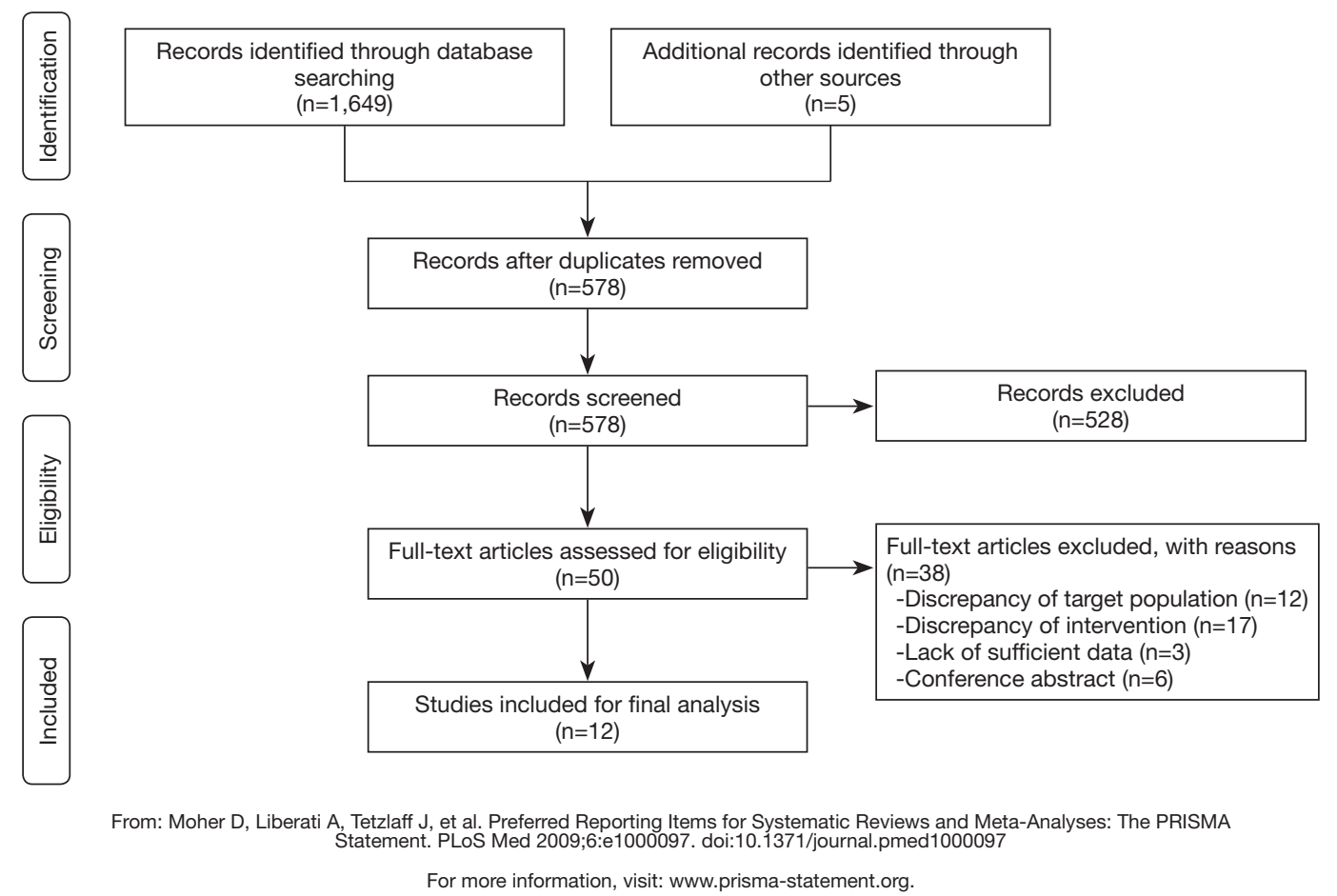

Figure 1 Flow diagram of the study selection.

2, moderate regression; grade 3, good regression; and grade 4, total regression [= complete pathological response (cPR)]. Patients with Dworak regression grade 0-2 were defined as non-responders and patients with Dworak grade 3-4 regression as responders.

Pathologic response was only assessed in 1 RCT and $3 \mathrm{UCT}$, and there were insufficient studies identified to conduct meta-analyses.

An improved pathological response was seen in the celecoxib arm with $61 \%$ of the patients (Dworak grade 3/4) compared to $35 \%$ in the placebo group. Also a trend towards a better cPR (Dworak grade 4) with the intervention of celecoxib was observed though not statistically significant. The number of patients with $\mathrm{T}$ - and $\mathrm{N}$-downstaging in the celecoxib group (72\%) was slightly larger than the placebo group (59\%) (30).

These findings are supported by the evidence from the UCTs. Both trials performed by Wang et al. (31) and Araujomino et al. (34) reported a better tumor regression grade (TRG) of pathology specimens after adding celecoxib to chemoradiotherapy compared with historical results. However, only Jakobsen et al. (32) did not see apparent pathological response.

\section{Overall response rate $(\mathrm{ORR})$ and disease control rate (DCR)}

ORR is defined as the percentage of patients who have a partial response (PR) or complete response (CR) to therapy. DCR is defined as the sum of CR, PR and stable disease. The CR is defined as the disappearance of all target lesions, and the PR means at least a $30 \%$ decrease in the sum of the target lesions. Stable disease is defined as fitting the criteria neither for progressive disease nor the PR.

Four RCTs (21,26-29), including 302 patients, reported ORR and DCR. Pooling all the four RCTs data together, we performed the meta-analysis.

When evaluating the effect on ORR (Figure 2), we used the random-effects model because of apparent heterogeneity $\left(\mathrm{P}_{\text {heterogeneity }}=0.01 ; \mathrm{I}^{2}=74 \%\right)$. The result of ORR $(\mathrm{RR}=1.09 ; 95 \% \mathrm{CI}, 0.62-1.92 ; \mathrm{P}=0.76)$ indicated that celecoxib combined with the routine chemotherapy did not significantly differ from chemotherapy alone.

When assessing the effect on DCR (as shown in Figure 2), we found out that no significant improvement of DCR was observed in the experimental group $(\mathrm{RR}=1.09 ; 95 \% \mathrm{CI}$, $0.94-1.27 ; \mathrm{P}=0.25$ by fixed effect, $\mathrm{I}^{2}=39 \%, \mathrm{P}_{\text {heterogeneity }}=0.18$ ).

Unfortunately, there were insufficient RCTs for any meaningful subgroup or sensitivity analyses. Three UCTs 
Table 1 Characteristics of each individual randomized controlled clinical trial

\begin{tabular}{|c|c|c|c|c|c|c|c|}
\hline First author/year & Phase & $\begin{array}{l}\text { Sample } \\
\text { size }(I / C)\end{array}$ & $\begin{array}{l}\text { Treatment measure } \\
\& \text { disease stage }\end{array}$ & Quality $^{\dagger}$ & \multicolumn{2}{|l|}{ Intervention } & $\begin{array}{l}\text { Outcome } \\
\text { measures }\end{array}$ \\
\hline Maiello/2006 & II & $39 / 38$ & $\begin{array}{l}\text { First line } \\
\text { chemotherapy; } \\
\text { III-IV }\end{array}$ & 18 & $\begin{array}{l}\text { Celecoxib } 400 \mathrm{mg} \text { po bid + FOLFIRI } \\
\text { regimen (irinotecan } 180 \mathrm{mg} / \mathrm{m}^{2} \text { day } 1 \text {, } \\
\text { together with leucovorin } 100 \mathrm{mg} / \mathrm{m}^{2} \\
\text { 5-FU } 400-600 \mathrm{mg} / \mathrm{m}^{2} \text { days } 1,2 \text { ) }\end{array}$ & $\begin{array}{l}\text { FOLFIRI } \\
\text { regimen }\end{array}$ & CR PR SD \\
\hline $\mathrm{Li} / 2015$ & NA & $26 / 26$ & $\begin{array}{l}\text { Second line } \\
\text { chemotherapy; } \\
\text { III-IV }\end{array}$ & 17 & $\begin{array}{l}\text { Celecoxib } 200 \text { mg po bid + S-1 } \\
(40 \mathrm{mg} \text {, bid) days } 1-14, \mathrm{q} 3 \mathrm{w}\end{array}$ & $\begin{array}{l}\mathrm{S}-1 \text { ( } 40 \mathrm{mg} \text {, } \\
\text { bid) days } 1-14 \text {, } \\
\text { q3w }\end{array}$ & ORR and DCR \\
\hline Debucquoy/2009 & II & $18 / 17$ & $\begin{array}{l}\text { Neoadjuvant } \\
\text { therapy; II-III }\end{array}$ & 25 & $\begin{array}{l}\text { Celecoxib } 400 \mathrm{mg} \text { po bid } \\
\text { +preoperative radiation ( } 45 \mathrm{~Gy} \text {; } \\
1.8 \mathrm{~Gy} / \text { fraction, } 5 \text { days } / \mathrm{w})+5 \text {-FU } \\
225 \mathrm{mg} / \mathrm{m}^{2} / \text { day }\end{array}$ & Placebo + CTR & $\begin{array}{l}\text { Dworak } \\
\text { regression; pCR; } \\
\text { T-downstaging, } \\
\text { N-downstaging }\end{array}$ \\
\hline
\end{tabular}

${ }^{\dagger}$, quality score based on downs and black list. Maximum score is 28. CP, control group; DCR, disease control rate; EP, experimental group; FA, folinic acid; MST, median survival times NA, not applicable; ORR, overall response rate; OS, overall survival; PR, partial response; pCR pathological complete response; SD, stable disease; 5-FU 5-fluorouracil.

reported outcomes about ORR and DCR in CRC patients. In Chen's study, although ORR was $31.9 \%$, the result indicated that adding celecoxib to irinotecan, 5-fluorouracil, and leucovorin (IFL) regimen did not improve ORR compared with what is expected from IFL alone (36). El-Rayes et al. (33) reported $4 \%$ ORR and $41 \%$ DCR with the agents of irinotecan, capecitabine, and celecoxib in 51 advanced CRC patients. However, these results were explained as comparable to most traditional combination chemotherapy regimens.

\section{Survival indices}

Because of the heterogeneity in outcome measures and data reporting methods, a meta-analysis of those RCTs could not be performed. We qualitatively summarized the results of those trials.

In RCTs, Jin et al. (29) reported a significantly decreased 3 -year mortality rate $(44.8 \%$ vs. $66.7 \%, \mathrm{P}=0.021)$ and an improved median survival time (MST), (28.4 vs. 22.9 months). In contrast, no significant effects of celecoxib on PFS or mortality rate of CRC patients were observed in the two other RCTs.

Three UCTs also investigated changes in survival indices, El-Rayes et al. (33) reported MST (21.1 months) and 1 year mortality rate $(75 \%)$. Both were in the range seen in most conventional treatment regimens. The conclusions from the other two single-arm phase II studies $(36,37)$ also indicated the lack of synergy between celecoxib and the historical regimens. Additionally, the trial conducted by Chan et al. (35) was terminated early because of the insufficiently promising clinical anti-tumor activity for this drug combination.

\section{Toxicities}

Finally, according to the National Cancer Institute Common Toxicity Criteria (version 2), we summarized 
Table 2 Characteristics of each individual non-controlled clinical trial

\begin{tabular}{|c|c|c|c|c|c|c|}
\hline First author/year & $\begin{array}{l}\text { Phase, study } \\
\text { designed }\end{array}$ & $\begin{array}{l}\text { Sample } \\
\text { size }\end{array}$ & $\begin{array}{l}\text { Treatment } \\
\text { measure \& } \\
\text { disease stage }\end{array}$ & Quality $^{\dagger}$ & Intervention & $\begin{array}{l}\text { Outcome } \\
\text { measures }\end{array}$ \\
\hline Araujomino/2018 & II, single-arm & 32 & $\begin{array}{l}\text { Neoadjuvant } \\
\text { therapy; Ila-III }\end{array}$ & 20 & $\begin{array}{l}\text { Celecoxib } 200 \mathrm{mg} \text { po bid + oxaliplatin } 50 \mathrm{mg} / \mathrm{m}^{2} \\
\text { day } 1+\text { capecitabine } 850 \mathrm{mg} / \mathrm{m}^{2} \text { days } 1-5\end{array}$ & $\mathrm{pCR}, \mathrm{SD}, \mathrm{SSS}$ \\
\hline Jakobsen/2008 & II, single-arm & 33 & $\begin{array}{l}\text { Neoadjuvant } \\
\text { therapy; Ila-Ilb }\end{array}$ & 17 & $\begin{array}{l}\text { Celecoxib } 400 \mathrm{mg} \text { po bid + UFT } 300 \mathrm{mg} / \mathrm{m}^{2}+ \\
\text { leucovorin } 22.5 \mathrm{mg} / \mathrm{d}+\text { preoperative radiation } \\
\text { (48.6-50 Gy } 1.8 \mathrm{~Gy} / \text { fraction) }\end{array}$ & TRG \\
\hline Chan/2011 & II, single-arm & 17 & $\begin{array}{l}\text { Second line } \\
\text { chemotherapy; } \\
\text { II-IV }\end{array}$ & 17 & Celecoxib 200 mg PO bid. + cetuximab 400 mg/m² & PR; SD; PD; PFS \\
\hline Chen/2018 & II, single-arm & 47 & $\begin{array}{l}\text { First line } \\
\text { chemotherapy; } \\
\text { II-IV }\end{array}$ & 21 & $\begin{array}{l}\text { Celecoxib } 400 \mathrm{mg} \text { po bid + IFL (irinotecan } \\
125 \mathrm{mg} / \mathrm{m}^{2}, 5 \text {-fluorouracil } 500 \mathrm{mg} / \mathrm{m}^{2} \text {, and } \\
\text { leucovorin } 20 \mathrm{mg} / \mathrm{m}^{2} \text { ) weekly } 1-4 \mathrm{w}\end{array}$ & $\begin{array}{l}\text { CR; PR; MST; } \\
\text { 1-year mortality } \\
\text { rate }\end{array}$ \\
\hline André/2006 & II, single-arm & 42 & $\begin{array}{l}\text { First line } \\
\text { chemotherapy; } \\
\text { II; III; IV }\end{array}$ & 23 & $\begin{array}{l}\text { Celecoxib } 400 \mathrm{mg} \text { po bid FOLFOX7 (oxaliplatin } \\
130 \mathrm{mg} / \mathrm{m}^{2} \mathrm{dL} \text { and LV } 400 \mathrm{mg} / \mathrm{m}^{2} \mathrm{dL} \text { and } \\
\text { continuous infusion of } 5-\mathrm{FU} 2,400 \mathrm{mg} / \mathrm{m}^{2} \text {, every } \\
2 \text { weeks for six cycles) }\end{array}$ & CR; PR; FPS; MST \\
\hline
\end{tabular}

${ }^{\dagger}$, quality score based on downs and black list. Maximum score is 28. CPCR, complete response; FA, folinic acid; FPS, progression-free survival; MST, median survival times; pCR pathological complete response; OS, overall survival; PD, progressive disease; PR, partial response; RRSD, surgical downstaging; SSS, sphincter-sparing surgery; TGR tumor regression grade; UFT uracil-tegafur.

A

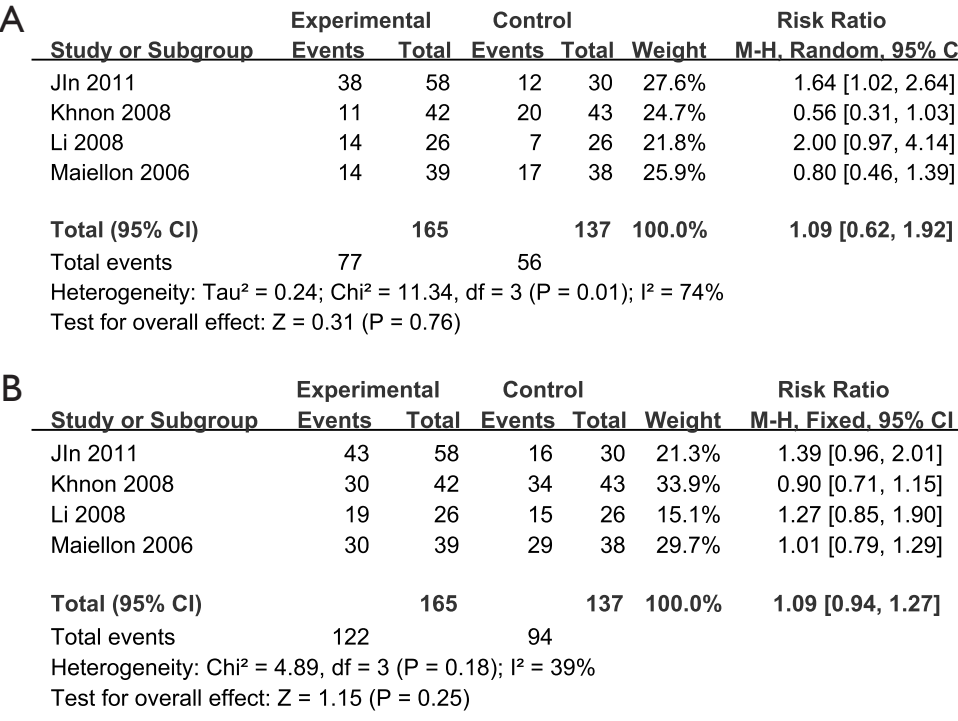

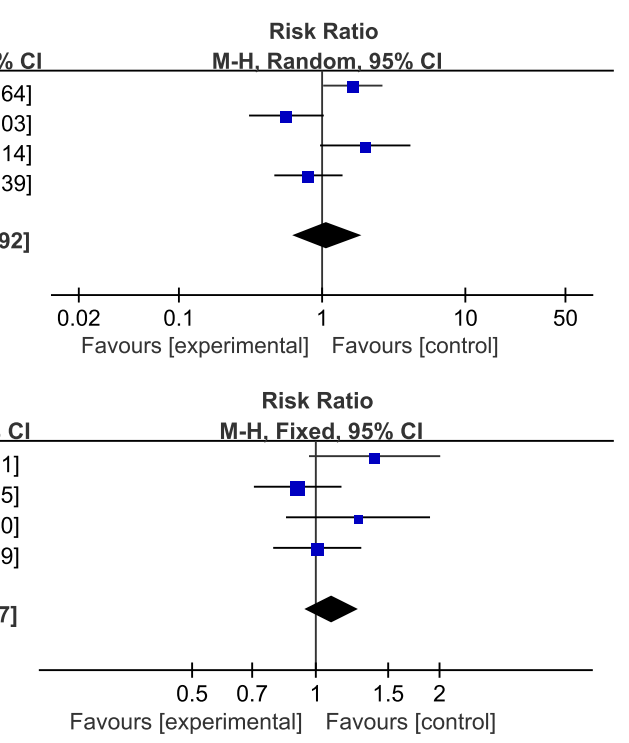

Figure 2 Forest plot of the (A) ORR and (B) DCR in patients with colorectal cancer randomly assigned to celecoxib versus placebo/no intervention. ORR, overall response rate; DCR, disease control rate. 
Table 3 Meta-analysis of the toxicities in patients with colorectal cancer randomly assigned to celecoxib or placebo/no intervention

\begin{tabular}{llllll}
\hline Toxicity & $\mathrm{N}$ & Experimental arm & Control arm & RR $(95 \% \mathrm{Cl})$ & Heterogeneity $\left(\mathrm{I}^{2} ; \mathrm{P}\right)$ \\
\hline Leucopenia & 4 & $49 / 125$ & $37 / 124$ & $1.32(0.96,1.82)$ & $0.0 \%, 0.80$ \\
Oral mucositis & 5 & $15 / 183$ & $30 / 154$ & $0.35(0.18,0.67)$ & $40 \%, 0.10$ \\
Diarrhea & 5 & $60 / 183$ & $55 / 154$ & $0.95(0.72,1.25)$ & $0.0 \%, 0.74$ \\
Nausea/vomiting & 5 & $63 / 183$ & $48 / 154$ & $1.07(0.79,1.44)$ & $0.0 \%, 0.95$ \\
cardiovascular toxicity & 3 & $6 / 118$ & $2 / 91$ & $2.46(0.49,12.29)$ & $0.0 \%, 0.27$ \\
\hline
\end{tabular}

$\mathrm{N}$, number of included studies; RR, relative risk.

grade 1-4 toxicities of included RCTs on adding celecoxib to conventional treatment in CRC patients. These specific toxicities included nausea/vomiting, diarrhea, cardiovascular toxicity, leucopenia and oral mucositis. Detailed data are shown in Table 3.

As expected, gastrointestinal toxicities (mainly grade $1-2)$ were most common. All these events were manageable, and celecoxib did not increase the gastrointestinal adverse events compared with the placebo group.

Our result indicated the risk of oral mucositis was significantly decreased with the addition of celecoxib. $(\mathrm{RR}=0.35 ; 95 \% \mathrm{CI}, 0.18-0.67 ; \mathrm{P}=0.002)$. A borderline significant risk of leukopenia in celecoxib group was evident after meta-analysis was performed ( $\mathrm{RR}=1.32 ; 95 \% \mathrm{CI}$, $0.96-1.82 ; \mathrm{P}=0.09$ ).

Amongst RCTs, no significantly increased risks of cardiotoxicities were found ( $\mathrm{RR}=2.46$; 95\% CI, 0.49-12.29; $\mathrm{P}=0.27)$. In UCTs, only one single-arm phase II trial reported that poor prognosis occurred in 6 patients, but all 6 patients had at least 1 cardiovascular risk factor at baseline (36).

The other finding of the meta-analysis was also supported by the evidence of UCTs. Gastrointestinal disturbances were the most common and the main adverse reactions were mild and manageable (grade 1-2). A major skin rash after celecoxib intervention was reported by Jakobsen (32), but this causal relationship has yet to be proven.

\section{Sensitivity analysis}

The sensitivity analysis was conducted with a fixed-effects model. When we removed the trial of the smallest and largest sample size, the results from all the meta-analysis did not significantly change compared with the results of the primary analysis.

\section{Discussion}

In this systematic analysis, we evaluated 12 clinical trials that included 621 CRC patients. The most consistent finding in our study is that celecoxib could be a useful adjuvant drug, especially in the neoadjuvant treatment of resectable CRC. Our summarized results indicated that celecoxib plus preoperation CRT could decrease TRG, increased cPR and sphincter-sparing surgery (SSS).

In vitro and in vivo experiments, COX-2 also has been found as a protector for tumor cells from radiation damage via downregulating the level of prostaglandins, which are tumor survival factors $(17,39,40)$.

Studies have suggested that the COX-inhibitor was a promising radiosensitizer, which could synergize with radiotherapy in the anti-tumor field $(17,30,31,34)$.

Some results of other published meta-analysis have proven the effectiveness on ORR/DCR of celecoxib or COX-2 inhibitors in non-small cell lung cancer, prostatic cancer and gastric cancer (41-43). However, in our present review, pooled data from longer-duration RCTs did not show the consistent effectiveness. Evidence from two eligible UCTs also did not show the great changes in ORR/ DCR with the concurrent administration of celecoxib. In the future, the efficacy on survival outcomes of the combination of celecoxib with other routine treatments for advanced unresectable CRC are required to be determined.

As with disease response rate, the effects of celecoxib on survival indices are not yet clear. There are conflicting evidence as to the impact of celecoxib on survival data. Although 4 studies reported significant or clinically meaningful benefits with concurrent usage of celecoxib, 5 studies reported no effect. These disparate and conflicting results can not be explained by the heterogeneity of outcome measures.

Immunohistochemical analysis of the biopsy and surgical 
specimens from patients was performed by Wang et al. The results suggested that COX-2 expression was correlated with overall and disease-free survival (DFS). Patients with COX-2 overexpressed seemed to have exacerbated DFS than those with low-level expression. Furthermore, the relationship between the administration of celecoxib and COX-2 expression in tumor tissue warrants investigation.

As with any therapeutic regimens, tolerance and adverse side-effects should be a major concern. Cardiovascular toxicities induced by the COX-2 inhibitor limit its applications for cancer. Furthermore, forecoxa, another Cox-2 inhibitor was withdrawn in 2004 because of its cardiac toxicity. A previous meta-analysis demonstrated that long-term use of celecoxib could lead to a significant risk of grade 3-4 cardiovascular events in varied tumor types (RR $=1.78 ; 95 \%$ CI, 1.30-2.43). Among eligible RCTs and UCTs in the present review, toxicities reported were generally graded 1-2 and cardiovascular adverse events were rarely reported. Cardiovascular toxicity of COX-2 inhibition is still a debated topic, and clinical monitoring of side effects, such as cardiovascular events, should be strengthened.

Additionally, gastrointestinal disorders, including nausea, vomiting, and diarrhea were frequently common with no significant difference observed between experimental and control arms. The low incidence of oral mucositis in the celecoxib group is in keeping with the known antiinflammatory effects of Cox-2 inhibition. A trend towards a statistical increase in the risk of leucopenia was shown after celecoxib intervention. It may suggest that COX2 plays a role in the recovery of the bone marrow after chemotherapy (44). These results may also be related to the dosage and duration of celecoxib treatment. Overall, the results of our meta-analysis indicated that the concurrent administration of celecoxib was well tolerated.

To the best of our knowledge, this is the first review evaluating the efficacy and safety of adding celecoxib to routine therapeutics for CRC patients. Our study provides several new viewpoints on the treatment of CRC. The results suggested that the pathological response rate can be significantly improved by adjuvant therapy of celecoxib in resectable CRC.

However, several limitations to this review should be pointed out. Firstly, there was substantial heterogeneity in the routine therapeutics, leading to inaccuracy when pooling and comparing individual data. Secondly, only a few RCTs met the inclusion criteria, so more clinical trials are required to confirm our findings. Thirdly, small sample sizes might attenuate the ability to detect meaningful changes in some studies.

The potential benefits of celecoxib implied COX-2 enzyme may be a promising target for cancer treatment. We believe that the combination of celecoxib and conventional therapeutics holds promise in CRC therapy field.

Our study aims to provide related empirical information on celecoxib in the treatment regimens of CRC to clinical practitioners and encourages interested investigators to conduct more mechanism investigations or RCTs.

In conclusion, celecoxib seems to be an effective and safe agent to synergize with chemoradiotherapy, improving pathological response rate for resectable CRC patients. The use of celecoxib is still recommended for CRC patients because rare obvious extension of cardiovascular adverse events was observed. Considering the insufficiency of present RCTs, we think future prospective and welldesigned RCTs with larger sample sizes are required to confirm our findings.

\section{Acknowledgments}

The authors gratefully acknowledge the staff in the Department of Medical Oncology, West China Hospital, Sichuan University and appreciate all the efforts Mrs. Tamanie Hood and Mr. Yuban Yang have contributed in commenting and editing this article.

Funding: None.

\section{Footnote}

Conflicts of Interest: All authors have completed the ICMJE uniform disclosure form (available at http://dx.doi. org/10.21037/tcr.2018.11.22). The authors have no conflicts of interest to declare.

Ethical Statement: The authors are accountable for all aspects of the work in ensuring that questions related to the accuracy or integrity of any part of the work are appropriately investigated and resolved.

Open Access Statement: This is an Open Access article distributed in accordance with the Creative Commons Attribution-NonCommercial-NoDerivs 4.0 International License (CC BY-NC-ND 4.0), which permits the noncommercial replication and distribution of the article with the strict proviso that no changes or edits are made and the original work is properly cited (including links to both the formal publication through the relevant DOI and the license). 
See: https://creativecommons.org/licenses/by-nc-nd/4.0/.

\section{References}

1. Binefa G, Rodriguez-Moranta F, Teule A, et al. Colorectal cancer: from prevention to personalized medicine. World J Gastroenterol 2014;20:6786-808.

2. Van Cutsem E, Cervantes A, Nordlinger B, et al. Metastatic colorectal cancer: ESMO Clinical Practice Guidelines for diagnosis, treatment and follow-up. Ann Oncol 2014;25 Suppl 3:iii1-9.

3. Saltz LB, Cox JV, Blanke C, et al. Irinotecan plus fluorouracil and leucovorin for metastatic colorectal cancer. Irinotecan Study Group. N Engl J Med 2000;343:905-14.

4. Douillard JY, Cunningham D, Roth AD, et al. Irinotecan combined with fluorouracil compared with fluorouracil alone as first-line treatment for metastatic colorectal cancer: a multicentre randomised trial. Lancet 2000;355:1041-7.

5. de Gramont A, Figer A, Seymour M, et al. Leucovorin and fluorouracil with or without oxaliplatin as first-line treatment in advanced colorectal cancer. J Clin Oncol 2000;18:2938-47.

6. Altorki NK, Christos P, Port JL, et al. Preoperative Taxane-Based Chemotherapy and Celecoxib for Carcinoma of the Esophagus and Gastroesophageal Junction: Results of a Phase 2 Trial. J Thorac Oncol 2011;6:1121-7.

7. Tseng CH. Metformin and endometrial cancer risk in Chinese women with type 2 diabetes mellitus in Taiwan. Gynecol Oncol 2015;138:147-53.

8. Verdoodt F, Kjaer SK, Friis S. Influence of aspirin and non-aspirin NSAID use on ovarian and endometrial cancer: Summary of epidemiologic evidence of cancer risk and prognosis. Maturitas 2017;100:1-7.

9. Tsujii M, Kawano S, Tsuji S, et al. Cyclooxygenase regulates angiogenesis induced by colon cancer cells. Cell 1998;93:705-16.

10. Iñiguez MA, Rodríguez A, Volpert OV, et al. Cyclooxygenase-2: a therapeutic target in angiogenesis. Trends Mol Med 2003;9:73-8.

11. Kirane A, Toombs JE, Ostapoff K, et al. Apricoxib, a Novel Inhibitor of COX-2, Markedly Improves Standard Therapy Response in Molecularly Defined Models of Pancreatic Cancer. Clin Cancer Res 2012;18:5031-42.

12. Leone V, Di PA, Ricchi P, et al. PGE2 inhibits apoptosis in human adenocarcinoma Caco-2 cell line through Ras-PI3K association and cAMP-dependent kinase A activation. Am J Physiol Gastrointest Liver Physiol 2007;293:G673.
13. Howe LR, Subbaramaiah K, Brown AM, et al. Cyclooxygenase-2: a target for the prevention and treatment of breast cancer. Endocr Relat Cancer 2001;8:97.

14. Ogino S, Kirkner GJ, Nosho K, et al. Cyclooxygenase-2 Expression is an Independent Predictor of Poor Prognosis in Colon Cancer. Clin Cancer Res 2008;14:8221.

15. Wülfing P, Diallo R, Müller C, et al. Analysis of cyclooxygenase-2 expression in human breast cancer: high throughput tissue microarray analysis. J Cancer Res Clin Oncol 2003;129:375-82.

16. Hida $\mathrm{T}$, Yatabe $\mathrm{Y}$, Achiwa $\mathrm{H}$, et al. Increased expression of cyclooxygenase 2 occurs frequently in human lung cancers, specifically in adenocarcinomas. Cancer Res 1998;58:3761-4.

17. Kishi K, Petersen S, Petersen C, et al. Preferential enhancement of tumor radioresponse by a cyclooxygenase-2 inhibitor. Cancer Res 2000;60:1326.

18. Whelton A, Fort JG, Puma JA, et al. Cyclooxygenase2--specific inhibitors and cardiorenal function: a randomized, controlled trial of celecoxib and rofecoxib in older hypertensive osteoarthritis patients. Am J Ther 2001;8:85-95.

19. Steinbach G, Lynch PM, Phillips RK, et al. The effect of celecoxib, a cyclooxygenase-2 inhibitor, in familial adenomatous polyposis. N Engl J Med 2000;342:1946.

20. Jacoby RF, Seibert K, Cole CE, et al. The Cyclooxygenase-2 Inhibitor Celecoxib Is a Potent Preventive and Therapeutic Agent in the Min Mouse Model of Adenomatous Polyposis. Cancer Res 2000;60:5040-4.

21. Downs SH, Black N. The feasibility of creating a checklist for the assessment of the methodological quality both of randomised and non-randomised studies of health care interventions. J Epidemiol Community Health 1998;52:377-84.

22. Deeks JJ. Issues in the selection of a summary statistic for meta-analysis of clinical trials with binary outcomes. Stat Stat Med 2002;21:1575-600.

23. Higgins JP, Thompson SG. Quantifying heterogeneity in a meta-analysis. Stat Med 2002;21:1539.

24. DerSimonian R, Laird N. Meta-analysis in clinical trials. Control Clin Trials 1986;7:177.

25. Higgins JP, Thompson SG, Deeks JJ, et al. Measuring inconsistency in meta-analyses. BMJ 2003;327:557-60.

26. Li YH, Xu XN. Efficacy of S-1 Plus Celecoxib for Advanced Colorectal Cancer in Elders: a Report of 26 Cases. J Clin Res 2015;32:862-5.

27. Maiello E, Giuliani F, Gebbia V, et al. FOLFIRI with or without celecoxib in advanced colorectal cancer: a 
randomized phase II study of the Gruppo Oncologico dell'Italia Meridionale (GOIM). Ann Oncol 2006;17 Suppl 7:vii55-9.

28. Kohne CH, De Greve J, Hartmann JT, et al. Irinotecan combined with infusional 5-fluorouracil/folinic acid or capecitabine plus celecoxib or placebo in the first-line treatment of patients with metastatic colorectal cancer. EORTC study 40015. Ann Oncol 2008;19:920-6.

29. Jin CH, Wang AH, Chen JM, et al. Observation of curative efficacy and prognosis following combination chemotherapy with celecoxib in the treatment of advanced colorectal cancer. J Int Med Res 2011;39:2129-40.

30. Debucquoy A, Roels S, Goethals L, et al. Double blind randomized phase II study with radiation+5-fluorouracil+/celecoxib for resectable rectal cancer. Radiother Oncol 2009;93:273-8.

31. Wang LW, Hsiao CF, Chen WT, et al. Celecoxib plus chemoradiotherapy for locally advanced rectal cancer: a phase II TCOG study. J Surg Oncol 2014;109:580-5.

32. Jakobsen A, Mortensen JP, Bisgaard C, et al. A COX2 inhibitor combined with chemoradiation of locally advanced rectal cancer: a phase II trial. Int J Colorectal Dis 2008;23:251-5.

33. El-Rayes BF, Zalupski MM, Manza SG, et al. PhaseII study of dose attenuated schedule of irinotecan, capecitabine, and celecoxib in advanced colorectal cancer. Cancer Chemother Pharmacol 2008;61:283-9.

34. Araujomino EP, Patt YZ, Murraykrezan C, et al. Phase II Trial Using a Combination of Oxaliplatin, Capecitabine, and Celecoxib with Concurrent Radiation for Newly Diagnosed Resectable Rectal Cancer. Oncologist 2018;23:2-e5.

35. Chan E, Lafleur B, Rothenberg ML, et al. Dual blockade of the EGFR and COX-2 pathways: A phase II trial of cetuximab and celecoxib in patients with chemotherapy refractory metastatic colorectal cancer. Am J Clin Oncol 2011;34:581-6.

Cite this article as: Zhou X, Wang X, Zhao Y, Yi C. The role of celecoxib for colorectal cancer treatment: a systematic review. Transl Cancer Res 2018;7(6):1527-1536. doi: 10.21037/ tcr.2018.11.22
36. Chen EY, Blanke CD, Haller DG, et al. A Phase II Study of Celecoxib With Irinotecan, 5-Fluorouracil, and Leucovorin in Patients With Previously Untreated Advanced or Metastatic Colorectal Cancer. Am J Clin Oncol 2018;41:1193-8.

37. André T, Tournigand C, Mineur L, et al. Phase II study of an optimized 5-fluorouracil-oxaliplatin strategy (OPTIMOX2) with celecoxib in metastatic colorectal cancer: a GERCOR study. Ann Oncol 2007;18:77-81.

38. Dworak O, Keilholz L, Hoffmann A. Pathological features of rectal cancer after preoperative radiochemotherapy. Int J Colorectal Dis 1997;12:19-23.

39. Davis TW, O'Neal JM, Pagel MD, et al. Synergy between celecoxib and radiotherapy results from inhibition of cyclooxygenase-2-derived prostaglandin E2, a survival factor for tumor and associated vasculature. Cancer Res 2004;64:279.

40. Milas L. Cyclooxygenase-2 (COX-2) enzyme inhibitors and radiotherapy: preclinical basis. Am J Clin Oncol 2003;26:S66-9.

41. James ND, Sydes MR, Mason MD, et al. Celecoxib plus hormone therapy versus hormone therapy alone for hormone-sensitive prostate cancer: first results from the STAMPEDE multiarm, multistage, randomised controlled trial. Lancet Oncol 2012;13:549-58.

42. Guo Q, Liu X, Lu L, et al. Comprehensive evaluation of clinical efficacy and safety of celecoxib combined with chemotherapy in management of gastric cancer. Medicine (Baltimore) 2017;96:e8857.

43. Dai P, Li J, Ma XP, et al. Efficacy and safety of COX2 inhibitors for advanced non-small-cell lung cancer with chemotherapy: a meta-analysis. Onco Targets Ther 2018;11:721-30.

44. Valcárcel M, Mendoza L, Hernández JJ, et al. Vascular endothelial growth factor regulates melanoma cell adhesion and growth in the bone marrow microenvironment via tumor cyclooxygenase-2. J Transl Med 2011;9:142. 
Table S1 Study quality assessment using downs and black checklist

\begin{tabular}{|c|c|c|c|c|c|c|c|c|c|c|c|c|}
\hline Criterion & Maiello 2006 & Kohne 2011 & Jin 2011 & Li 2015 & Debucquoy 2009 & Elrayes 2008 & Araujomino 2018 & Jakobsen 2008 & Chan 2011 & Wang 2013 & Chen 2018 & André 2006 \\
\hline \multicolumn{13}{|l|}{ Reporting } \\
\hline Q1: Objective clearly described & 1 & 1 & 1 & 1 & 1 & 1 & 1 & 1 & 1 & 1 & 1 & 1 \\
\hline Q2: Outcomes clearly described & 1 & 1 & 1 & 1 & 1 & 1 & 1 & 1 & 1 & 1 & 1 & 1 \\
\hline $\begin{array}{l}\text { Q3: Patients characteristics clearly } \\
\text { described }\end{array}$ & 1 & 1 & 1 & 1 & 1 & 1 & 1 & 1 & 1 & 1 & 1 & 1 \\
\hline Q4: Interventions clearly described & 1 & 1 & 1 & 1 & 1 & 1 & 1 & 1 & 1 & 1 & 1 & 1 \\
\hline $\begin{array}{l}\text { Q5: Principal confounders clearly } \\
\text { described }\end{array}$ & 0 & 1 & 1 & 1 & 1 & 0 & 0 & 0 & 0 & 1 & 1 & 1 \\
\hline Q6: Main findings clearly described & 1 & 1 & 1 & 1 & 1 & 1 & 1 & 1 & 1 & 1 & 1 & 1 \\
\hline $\begin{array}{l}\text { Q7: Random variability for the main } \\
\text { outcome provided }\end{array}$ & 1 & 1 & 1 & 1 & 1 & 1 & 1 & 1 & 1 & 1 & 1 & 1 \\
\hline Q8: Adverse events reported & 1 & 1 & 1 & 1 & 1 & 1 & 1 & 1 & 1 & 0 & 1 & 1 \\
\hline $\begin{array}{l}\text { Q9: Characteristics of patients lost to } \\
\text { follow-up described }\end{array}$ & 0 & 1 & 1 & 1 & 1 & 1 & 0 & 0 & 1 & 1 & 1 & 1 \\
\hline Q10: Actual P value reported & 0 & 1 & 1 & 0 & 1 & 1 & 1 & 1 & 1 & 1 & 1 & 1 \\
\hline \multicolumn{13}{|l|}{ External validity } \\
\hline $\begin{array}{l}\text { Q11: Sample asked to participate } \\
\text { representative of the population }\end{array}$ & UTD/0 & UTD/0 & 1 & UTD/0 & 1 & UTD/0 & 1 & UTD/0 & UTD/0 & 1 & UTD/0 & 1 \\
\hline $\begin{array}{l}\text { Q12: Sample agreed to participate } \\
\text { representative of the population }\end{array}$ & UTD/0 & UTD/0 & 1 & UTD/0 & 1 & UTD/0 & 1 & UTD/0 & UTD/0 & 1 & UTD/0 & 1 \\
\hline $\begin{array}{l}\text { Q13: Staff participating representative } \\
\text { of the patient's environment }\end{array}$ & 1 & 1 & 1 & 1 & 1 & 1 & 1 & 1 & 1 & 1 & 1 & 1 \\
\hline \multicolumn{13}{|l|}{ Internal validity-bias } \\
\hline Q14: Attempt to blind participants & 0 & 0 & 1 & 0 & 1 & 0 & 1 & 1 & 1 & 0 & 1 & 0 \\
\hline Q15: Attempt to blind assessors & 0 & 0 & 1 & 0 & 1 & 0 & 1 & 1 & 1 & 0 & 1 & 0 \\
\hline $\begin{array}{l}\text { Q16: Any data dredging results stated } \\
\text { clearly }\end{array}$ & 1 & 1 & 1 & 1 & 1 & 1 & 1 & 1 & 1 & 1 & 1 & 1 \\
\hline $\begin{array}{l}\text { Q17: Analyses adjusted for different } \\
\text { lengths of follow-up }\end{array}$ & 1 & 1 & 1 & 1 & 1 & 1 & 1 & 1 & 1 & 1 & 1 & UTD/0 \\
\hline Q18: Appropriate statistics & 1 & 1 & 1 & 1 & 1 & 1 & 1 & 1 & 1 & 1 & 1 & 1 \\
\hline Q19: Reliable intervention compliance & 1 & UTD/0 & 1 & UTD/0 & UTD/0 & UTD/0 & 1 & 1 & 0 & 1 & 1 & 1 \\
\hline Q20: Accurate outcome measures & 1 & 1 & 1 & 1 & 1 & 1 & 1 & 1 & UTD/0 & 1 & UTD/0 & 1 \\
\hline \multicolumn{13}{|l|}{$\begin{array}{l}\text { Internal validity (selection bias) and } \\
\text { power }\end{array}$} \\
\hline $\begin{array}{l}\text { Q21: Participants recruited from same } \\
\text { population }\end{array}$ & 0 & 1 & 1 & 0 & 0 & 1 & 0 & 0 & 0 & 1 & 0 & 1 \\
\hline $\begin{array}{l}\text { Q22: Participants recruited at the } \\
\text { same time }\end{array}$ & 1 & 1 & 1 & 1 & 1 & 1 & 1 & 1 & 1 & 1 & 1 & 1 \\
\hline Q23: Randomised & 1 & 1 & 1 & 1 & 1 & 0 & 0 & 0 & 0 & 0 & 0 & 0 \\
\hline $\begin{array}{l}\text { Q24: Adequate allocation } \\
\text { concealment }\end{array}$ & 1 & 1 & 1 & UTD/0 & 1 & 0 & 0 & 0 & 0 & 1 & 0 & 1 \\
\hline $\begin{array}{l}\text { Q25: Adequate adjustment for } \\
\text { confounders }\end{array}$ & 1 & 1 & 1 & 0 & 1 & 0 & 0 & 0 & 0 & 1 & 1 & 1 \\
\hline Q26: Loss of follow-up reported & UTD/0 & 1 & 1 & 1 & 1 & 1 & UTD/0 & 0 & 1 & 1 & 1 & 1 \\
\hline Q27: Power calculation & 1 & 1 & 0 & 0 & 1 & 0 & 1 & 0 & 0 & 0 & 1 & 1 \\
\hline Total & 18 & 22 & 26 & 17 & 25 & 17 & 20 & 17 & 17 & 22 & 21 & 24 \\
\hline
\end{tabular}

Key: $1=$ yes; $0=$ no; UTD $=0$, (unable to determine). Maximum score: 28 . 